\title{
Effect of Search Algorithm Execution Time Analysis Education on Logical Thinking of Elementary School Student
}

\author{
bong chul Kim ${ }^{1}$, gi pyo Kong ${ }^{2}$, jonghoon $\mathrm{Kim}^{3}$ \\ Jeju national university \\ 1'pankun@naver.com, ${ }^{2} k k c c 88 @ l y c o s . c o . k r,{ }^{3} j k i m 0858 @ j e j u n u . a c . k r$
}

\begin{abstract}
The purpose of this study is to develop a Python search algorithm educational program based on execution time to improve the logical thinking of elementary school students. This educational program was developed based on the process of ADDIE model, utilizing the results of pre-demand analysis conducted for 133 students in elementary school in OO. In order to verify the effectiveness of the developed education program, 25 students who participated in the education donation program at University conducted 42 hours of classes during 6 days. The GALT test was used to analyze the educational effects of the pre-and post-test. The results of the analysis show that the SW education program developed in this study can positively affect the logic of elementary school students.
\end{abstract}

Keywords: Software education, Search algorithm, Algorithm execution time

\section{Introduction}

There are various kinds of educational programming languages made for software education. Nevertheless, it is appropriate to approach with languages that are easy to learn and can be expanded to various forms of application programs while letting students have interest [1]. If a text language is learned, because the transferability to a different text programming language is high, it is easy to accumulate basic programming knowledge and structure, and use and apply that knowledge to program development. Although it takes a long time to become familiar with a text programming language, it is favorable for complex programming and helpful for improvement of computational thinking compared to block-type programming languages, according to a study result [2]. However, majority of elementary education sites use educational programming languages for block-based coding such as Entry and Scratch because they facilitate easy initial entry stage and have many elements that can be approached with interest.

Therefore, this study used Python, a text programming language, to improve the logical thinking of elementary school students. Furthermore, after performing preliminary requirement analysis, textbooks and programs were developed by focusing on the comparison and analysis of execution time for search algorithms using Python. Among grade four, five, and six students of elementary school, the volunteer sample of 25 students were targeted. The logical thinking was classified by using six logical thinking ability factors of Group Assessment of Logical Thinking (GALT) questionnaire: preservation, ratio, variable control, probability, correlation, and combination.

Article history:

Received (March 17, 2019), Review Result (July 14, 2019), Accepted (August 10, 2019) 


\section{Theoretical background}

\subsection{Software education}

The software education aims to foster creative/convergent talents. It is an education that improves people's ability to use "computational thinking" to solve problems occurring in real life based on information ethical consciousness and attitude through three domains of "life and software", "algorithm and programming", and "computing and problem solving" [3]. Because studies have been actively conducted for software education in relatively recent years, the conceptual classification of software education has not been clearly agreed upon yet. However, it can be called an education method that commonly focuses more on the problem solving ability improvement of students through "computational thinking" [4][5].

\subsection{Search algorithm}

A search algorithm searches data that satisfies certain criteria or property in data stored in memory space or a given input data set, and it is a most fundamental algorithm in school subjects of data structure and algorithm. Search algorithm is very widely used in real programming, but it is also known as an easy algorithm for education because its basic concept is simple and intuitive [6][7].

This study compares mainly linear search and binary search algorithms among search algorithms to analyze the execution time: the linear search method finds desired data in a given data set from the beginning sequentially, and the binary search method searches a sorted data set by dividing it in half.

\subsection{Algorithm execution time}

Algorithm execution time refers to time taken by the algorithm to solve a certain problem. It is an important criterion for evaluating an algorithm's performance because the efficiency of computer is determined based on how long it takes even if a same result is derived when solving a same problem. Algorithm execution time is also called time complexity and can be analyzed by measuring the execution frequency of command statement. This study focuses on algorithm education, through which students ponder about how to solve a problem in minimal time and its importance, beyond simply solving the problem[8].

\section{Study method}

\subsection{Study subjects}

To investigate the effect of program developed in this study, an education contribution program was conducted at OO University. 25 students were selected for the volunteer sample based on program volunteering sampling. The grade and gender of study subjects are shown in Table 1.

\subsection{Education program}

In this study, an education program was developed, as shown in Table 2, according to ADDIE model of Dick and Carey, which is one of models of educational program development. A total of five stages, i.e., analysis, design, development, implementation, and evaluation were performed in sequence, and in accordance with the learners' requirement analysis result, the 
education program was designed and developed, implemented through classes, and evaluated the result through the logical thinking test.

Table1. Grade and gender of the subject

\begin{tabular}{c|c|c|c}
\hline class & Male & Female & Total \\
\hline \hline 4 Grade & 5 & 0 & 5 \\
\hline 5 Grade & 6 & 2 & 8 \\
\hline 6 Grade & 7 & 5 & 12 \\
\hline Total & 18 & 7 & 25 \\
\hline
\end{tabular}

Table 2. Educational program development plan

\begin{tabular}{c||c}
\hline \multicolumn{1}{c||}{ Analysis } & $\begin{array}{c}\text { Analysis of learners } \\
\text { Preliminary requirement analysis (survey } \\
\text { targeting upper grade students) }\end{array}$ \\
\hline Design & $\begin{array}{c}\text { Goal set up and tool selection } \\
\text {-Effect of education on execution time of } \\
\text { search algorithm using Python } \\
\text { Evaluation tool design }\end{array}$ \\
\hline -Logical thinking test (GALT) \\
\hline Development & $\begin{array}{c}\text { Teaching/learning plan (42 hour-lessons) } \\
\text { Student activity sheet (42 hour-lessons) }\end{array}$ \\
\hline Implementation & $\begin{array}{c}\text { Implementation of software education } \\
\text { Evaluation }\end{array}$ \\
\hline
\end{tabular}

\subsubsection{Requirement analysis}

This study used Rossett's requirement analysis model according to the procedure of ADDIE model. Rossett's model is an education requirement analysis model used in corporate training, and provides easy-to-apply information to people performing the requirement analysis. The requirement analysis was conducted with 133 grade six elementary school students (72 males and 61 females). 
Table 3. SW education using tool $(\mathrm{N}=82)$

\begin{tabular}{c|c}
\hline Tools & Students \\
\hline \hline EPL(Scratch, entry etc) & $52(63.4 \%)$ \\
Physical Computing & $19(23.2 \%)$ \\
Unplugged & $6(7.3 \%)$ \\
Computer language & $4(4.9 \%)$ \\
\hline
\end{tabular}

Table 3 shows the results of investigating class tools mainly used in the software education by students who have had software education experience $(\mathrm{N}=82)$. In a majority of cases, the education was conducted using EPL (Scratch, Entry, etc.), which was followed by Physical Computing. On the other hand, the use of computer language occupied the lowest proportion.

\section{Table 4. Necessity of algorithm execution time training}

\begin{tabular}{c|c}
\hline Necessity & Students \\
\hline \hline Very likely & $14(10.5 \%)$ \\
Somewhat likely & $24(18 \%)$ \\
Neutral & $78(58.6 \%)$ \\
Somewhat unlikely & $8(6 \%)$ \\
Very unlikely & $9(6.8 \%)$ \\
\hline
\end{tabular}

Table 4 shows the necessity of education for algorithm execution time. A majority answered "Neutral" (don't know), and it was guessed that the concept of "algorithm execution time" was somewhat difficult or strange to the students. The positive replies $(28.5 \%)$ had higher proportion than the negative replies (12.8\%).

\subsubsection{Design and development of program}

In order to design a software education program using Python, the learning level of education targets and difficulty level of programming were taken into consideration. Particularly, by selecting linear search, which is the most basic method among the search algorithms, and binary search, which is easy to understand for even elementary school students, the textbook was composed to facilitate comparative analysis of execution time. The learning themes are shown in Table 5 below.

\subsection{Study design and treatment}

Targeting 25 elementary school students between grade four and six, inclusively, in the province, this study conducted 42 lessons in six days including orientation, pre-/post-test of logical thinking, and project presentation.

To prove the effect of education program, pre-test and post-test were conducted by using GALT, a logical thinking test. 
Table 5. The theme of education program

\begin{tabular}{|c|c|}
\hline & Learning Theme \\
\hline $1-7$ & $\begin{array}{c}\cdot \text { Orientation } \\
\text {-Learning Python basic functions } \\
\text { •Input of pre-test }\end{array}$ \\
\hline $9-14$ & $\begin{array}{l}\text { •Print, Input code practice } \\
\text { •Practice random code } \\
\text { •Practice arithmetic, condition code }\end{array}$ \\
\hline $15-21$ & $\begin{array}{l}\text {-Utilize code we have learned } \\
\text { •Practice list code }\end{array}$ \\
\hline $22-28$ & $\begin{array}{l}\text {-Understanding Linear search } \\
\text {-Understanding Binary search }\end{array}$ \\
\hline $29-35$ & $\begin{array}{l}\text {-Creating a project plan for individual projects } \\
\cdot \text { Creating individual project objects. }\end{array}$ \\
\hline $36-42$ & $\begin{array}{l}\text {-Present your individual project work } \\
\text { •Input of post-test }\end{array}$ \\
\hline
\end{tabular}

\section{Study results}

\subsection{Verification of education program}

Investigation was preformed to analyze what kind of effect was made on the logical thinking of students by Python's search algorithm-based execution time SW education.

\subsubsection{Pre-test and post-test of logical thinking}

To investigate the change of logical thinking in the pre-test and post-test results, the paired t-test was performed for the factors that satisfied the normality, and the Wilcoxon signed-rank test, a non-parametric test, was performed for the factors that did not satisfy the normality.

Table 6. Changes in logical thinking(paired T-test)

\begin{tabular}{|c|c|c|c|c|c|c|c|}
\hline \multirow{2}{*}{ Subscale } & \multirow{2}{*}{$\mathrm{N}$} & \multicolumn{2}{|c|}{ Pre-Test } & \multicolumn{2}{|c|}{ Post-Test } & \multirow{2}{*}{$\mathrm{t}$} & \multirow[t]{2}{*}{$\mathrm{p}$} \\
\hline & & M & $\mathrm{SD}$ & M & SD & & \\
\hline Ratio & 25 & 2.56 & 1.895 & 3.08 & 2.178 & -2.116 & $.045^{*}$ \\
\hline Probability & 25 & 1.16 & .943 & 1.20 & .764 & -.189 & .852 \\
\hline
\end{tabular}

In the paired t-test results, the mean score of "Ratio" was increased by 0.52 point from 2.56 to 3.08 , and the p-value was 0.045 , showing that a significant increase occurred in the mean score. On the other hand, in the case of "Probability", the mean was increased by 0.04 point from 1.16 to 1.20 , but the p-value was 0.854 , showing that it was not significant. 
Table 7. Changes in logical thinking(Wilcoxon's test)

\begin{tabular}{c|c|c|c|c|c|c|c}
\hline \multirow{2}{*}{ Subscale } & \multirow{2}{*}{$\mathrm{N}$} & \multicolumn{2}{|c|}{ Pre-Test } & \multicolumn{2}{|c|}{ Post-Test } & \multirow{2}{*}{$\mathrm{Z}$} & $\mathrm{p}$ \\
\cline { 3 - 7 } \cline { 3 - 7 } & & $\mathrm{M}$ & $\mathrm{SD}$ & $\mathrm{M}$ & $\mathrm{SD}$ & & \\
\hline \hline Preservation & 25 & 2.88 & 1.054 & 3.24 & .879 & $-2.000^{\mathrm{b}}$ & $.046^{*}$ \\
\hline Variable control & 25 & 1.48 & 1.418 & 1.64 & 1.497 & $-1.155^{\mathrm{b}}$ & .248 \\
\hline Correlation & 25 & .240 & .436 & .400 & .577 & $-1.414^{\mathrm{b}}$ & .157 \\
\hline Combination & 25 & 1.20 & .707 & 1.60 & .645 & $-2.500^{\mathrm{b}}$ & $.012^{*}$ \\
\hline
\end{tabular}

${ }^{*} \mathrm{p}<.05 * * \mathrm{p}<.01, \quad$ b. based on the rank of negative

In the results of signed-rank test for the factors that did not satisfy the normality in Table 7 , the mean score of "Preservation" showed 0.36 point increase from 2.88 to 3.24 , and the p-value of 0.046. The mean score of "Combination" showed 0.40 point increase from 1.20 to 1.60 , and the p-value of 0.012. In other words, the mean score increased significantly for "Preservation" and "Combination", respectively. On the other hand, the mean score of "Variable Control" showed increase by 0.16 point from 1.48 to 1.64 and that of "Correlation" increased by 0.16 point from 0.24 to 0.4 , but they were not significant because $\mathrm{p}<0.05$ was not satisfied.

\section{Conclusion}

To improve the logical thinking for elementary school students in $\bigcirc \circ$ Province, this study introduced a search algorithm-based education program using Python, and developed and applied the education program according to the development stages of ADDIE model. In order to easily control external factors while proceeding with the education and increase the reliability of study, an intensive project education was conducted for 42 lessons in a total of six days by using a holiday period instead of conducting weekend classes during a school semester. Furthermore, assignments related to contents that had been learned already and that would be learned in future were given every day, and the students were supervised to perform the assignments so that dense learning can be achieved in a short period of time. Based on the results of pre-test and post-test of logical thinking, it is confirmed that the SW education using the education program developed in this study can have positive effect on the logical thinking of elementary school students.

However, there was limitation in generalizing the result of this study because the experimental group of this study did not satisfy the requirement of at least 30 participants, which was required for the correlation study. Furthermore, because only the experimental group was injected without control group in the education program developed in this study, there was a problem that the correlation could not be analyzed to investigate whether the positive effect on the logical thinking was an effect of the education program developed in this study or not. Furthermore, because of limited time constraint, the comparative analysis of execution time was performed for only the linear search and the binary search in the search algorithm education, and there was a limitation for the students to implement them on their own. In a future study, an experimental group and a control group will be composed with 30 participants or more, and comparative analysis of correlation between factors will be performed.

\section{References}

[1] K. Kim \& H. Kim. "A Case Study on Necessity of Computer Programming for Interdisciplinary Education”, Journal of Digital Convergence, Vol.12, No.11, pp.339-348, (2014) DOI: 10.14400/JDC.2014.12.11.339 
[2] Seo, Sung Won. "The Effect of Computational Thinking Ability using TPL and VPL with Robot Programming Education”,Korea National University of Education. Master's Thesis. (2010)

[3] Kim, H. "A Study of the Direction for Developing Software Education Operating Guide". Korean Association for Learner-centered Curriculum and Instruction, Vol.16, No.8, pp.529-548. (2016)

[4] Sung, Jungsook, Hyeoncheol Kim. "Analysis on the International Comparison of Computer Education in Schools". The Journal of Korean association of computer education, Vol.18, No.1, pp.45-54. (2015)

[5] Wing, J. M. "Computational thinking and thinking about computing”. Royal Society of London. Philosophical Transactions Vol.366, No.1881, pp.3717-3726. (2008). DOI: 10.1098/rsta.2008.0118

[6] Jeoung, Inkee, "Development of S/W Component for Search Algorithm Education". Journal of the Korean Association of Information Education, Vol.6, No.2, pp.179-186 (2002)

[7] Kim, Jong-hoon \& Kim Jong-Jin. “An introduction to computers”. Seoul: Hanbit publishing co. (2013)

[8] Computer Language Dictionary Compilation Committee. Computer Internet IT Dictionary. Iljin publishing co. (2005) 
